\title{
Comparison between Rayleigh and Mie Scattering Assumptions for Z-R Relation and Rainfall Rate Estimation with TRMM/PR Data
}

\author{
Kohei Arai \\ Graduate School of Science and Engineering \\ Saga University \\ Saga City, Japan
}

\begin{abstract}
Comparison of the rain rate estimated with the assumptions of Rayleighand Mie scattering is made. We analyzed the different relationships between the radar reflective factor and rain rate (so-called $Z-R$ relationship) with both scattering models for different DSD (droplet size distribution) and rainfall types as the wavelength is $2.2 \mathrm{~cm}$ which is in accord with the band of TRMM/PR. Meanwhile we introduced a discrete ordinates method to retrieve the $Z-R$ relationship for Mie scattering assumption. It is found that the retrieval result can be represented as the sum of some simple $Z-R$ relationships. By the analysis of the $Z-R$ relationships estimated from Rayleigh and Mie scattering assumptions in the rain types, we found that the difference of $Z-R$ relationships between Rayleigh and Mie scattering in the thunderstorm that represents the larger raindrop size is larger than that in the drizzle that represent the smaller raindrop size.
\end{abstract}

Keywords-TRMM/PR; Precipitation; Z-R Relation; Rainfall Rate; Rayleigh scattering; Mie scattering; Droplet size distribution; RadarReflectivity Factor;

\section{INTRODUCTION}

Rainfall rate estimation of the Tropical Rainfall Measuring Mission: TRMM carries Precipitation Radar: PR is based on Z-R Relation ( $\mathrm{Z}$ denotes radar reflectance factor, while $\mathrm{R}$ denotes rainfall rate)[1]. In order to estimate $Z$ factor, attenuation due to rainfall and scattering due to raindrops is taken into account. Scattering due to raindrops depends on droplet size distribution under Rayleigh or Mie scattering assumptions. If the droplet size is greater than $\lambda / 8$ ( $\lambda$ denotes wavelength), then Mie scattering assumption is appropriate while that is less than $\lambda / 8$, then Rayleigh scattering is assumed. Usually, Rayleigh scattering is assumed for rainfall rate estimation of TRMM/PR empirically [2], [3], [4].

It is reported that Mie scattering based $\mathrm{Z}$ factor estimation is better than that of Rayleigh scattering based estimation [5],[6]. Although these reports deal with influence due to different assumptions, Rayleigh and Mie scattering on $\mathrm{Z}$ factor estimation, there is no report which discuss the influence on rainfall rate estimation. The reason for this is difficulty on definition of Z-R Relation which is taken into account rainfall types [10], atmospheric conditions, topological effect, etc. There is a paper related to radar meteorology which deals with Z-R Relation based on empirical exponential law of 69 of different rainfall types, weather conditions, written by Battan
[7]. Also difficulty is caused by complicated computations of backscattered reflection factor based on Mie scattering assumption.

In this paper, rainfall rate estimation method based on Mie scattering is proposed together with some experimental background data for validation of the proposed method. Firstly, Z-R Relation based on Rayleigh and Mie scattering assumptions for three rainfall types, stratiform, drizzling, and thunder storm theoretically. Then both influences of the different scattering assumptions on Z-R Relation and rainfall rate estimations. There is $\mathrm{mm}$ order of droplet size according to Marshall and Palmer [9]. Wavelength of TRMM/PR is $22 \mathrm{~mm}$ [8] so that Rayleigh limitation is situated at $2.75 \mathrm{~mm}$. Therefore, it is better to adopt Mie scattering assumption for rainfall rate estimation for such large droplet size of rainfall.

The following section describes theoretical background of rainfall estimation followed by experimental data for validation of the proposed method. Then conclusion is described together with some discussions.

\section{THEORETICAL BACKGROUND}

\section{A. Estimation of Rayleigh and Mie Scattering Based Z-R Relations}

Averaged received reflectance can be represented as equation (1),

$\eta=\int_{v o l} \sigma_{b} N(D) d D=\frac{\pi^{5}}{\lambda^{4}}|K|^{2} \int_{0}^{D_{\max }} D^{6} N(D) d D$

where $\mathrm{K}$ denotes abruption coefficient of water and ice crystal while D denotes droplet radius, N(D) denotes size distribution and $\sigma$ denotes backscattering cross section. Radar reflection factor, $\mathrm{Z}$, then is represented in equation (2),

$$
Z=\int_{0}^{D_{\max }} D^{6} N(D) d D
$$

On the other hand, Mie scattering based $\mathrm{Z}$ factor is expressed as equation (3),

$$
Z_{\text {Mie }}=\frac{\lambda^{4}}{\pi^{5}|K|^{2}} \int_{0}^{D_{\max }} \sigma_{\text {Mie }} N(D) d D
$$

Then rainfall rate can be written in equation (4),

$$
R=6 \pi * 10^{-4} \int_{0}^{D_{\max }} D^{3} N(D) \nu(D) d D
$$


Where $v(D)$ denotes droplet falling speed which is used to be represented as a function of droplet size. In this paper, exponential representation $v(D)=c D^{r}$ is used as usual. This is validated by Atlas and Ulbrich for the case, $c=3.778$ and $\gamma=0.67$ [11]. Gunn and Kitnzer proves that this equation show a good coincidence with the calculation results of rainfall rate for the raindrop radius ranged from 0.5 to $5.0 \mathrm{~mm}$ [12]. N(D) denotes droplet size distribution and is represented as equation (5) of gamma distribution proposed by Ulbrich [13],

$N(D)=N_{0} D^{\mu} \exp (-\Lambda D)$

Where $\mathrm{N}_{0}$ denotes $\mathrm{N}$ axis cross section of droplet size distribution while $\mathrm{D}^{*}$ denotes the factorial of power law of raindroplet size distribution. Meanwhile, $\mu$ denotes slope droplet size distribution in logarithmic-logarithmic expression. When $\mu=0$, then $D^{\mu}=1$. On the other hand, $\Lambda$ defines exponential function based droplet size distribution, $\Lambda=\alpha R^{\beta}$. Thus $\mathrm{Z}$ factor can be represented as equation (6) and (7) using equations (2), (4) and (5) based on integral conversion of Gamma function [14].

$$
\begin{aligned}
Z & =\int_{0}^{D_{\max }} D^{6} N_{0} D^{\mu} \exp (-\Lambda D) d D=\frac{N_{0}}{\Lambda^{7+\mu}} \Gamma(7+\mu) \\
R & =6 \pi * 10^{-4} \int_{0}^{D_{\max }} D^{3} N_{0} D^{\mu} \exp (-\Lambda D)^{*} 3.778 * D^{0.67} d D \\
& =6 \pi * 10^{-4} * 3.778 * \frac{N_{0}}{\Lambda^{4.67+\mu}} \Gamma(4.67+\mu)
\end{aligned}
$$

where $\Gamma(x)$ denotes Gamma function. $\Lambda$ can be obtained from the equation (7) the Z-R Relation can be reduced as follows,

$Z=a R^{b}$

Droplet size distribution is not so easy to estimated results in difficulty on determination of $\mathrm{a}, \mathrm{b}$ coefficients. In general, droplet size distribution can be estimated with several actual observed data of $\mathrm{Z}$ factors based on iteration and /or regression [15], [16].

On the other hand, Mie scattering based Z-R Relation cannot be estimated with backscattering coefficients $\sigma_{\text {Mie }}$ and droplet size distribution derived Gamma function of integral conversion.

Therefore, $\sigma_{\text {Mie }}$ has to be expanded with Legendre function expansion as shown in equation (9),

$\sigma_{\text {Mie }}(D)=r_{0} P_{0}(D)+r_{1} P_{1}(D)+r_{2} P_{2}(D)+\ldots+r_{n} P_{n}(D)$

where

$$
P_{0}(D)=1, P_{1}(D)=D, P_{2}(D)=\frac{1}{2}\left(3 D^{2}-1\right), P_{3}(D)=\frac{1}{2}\left(5 D^{3}-3 D\right), \ldots
$$

[17]. $\sigma_{\text {Mie }}$ for droplet size of D can be estimated based on Mie scattering theory [16]. The coefficients of $\sigma_{\text {Mie }}$ of the equation (9) $\left\{r_{0}, r_{1}, r_{2}, \ldots, r_{n}\right\}$ can then be obtained through least square method with $\sigma_{\text {Mie }}$ for each droplet size estimated based on Mie scattering theory.
Meanwhile, there is the following relation between Legendre function $\left\{P_{0}, P_{1}, P_{2}, \ldots, P_{n}\right\}$ and droplet size as follows,

$$
\begin{aligned}
Z_{\text {Mie }} & =\frac{\lambda^{4}}{\pi^{5}|K|^{2}}\left(a_{0} \int_{0}^{D_{\max }} N(D) d D+a_{1} \int_{0}^{D_{\max }} D N(D) d D+\ldots+a_{n} \int_{0}^{D_{\max }} D^{n} N(D) d D\right) \\
& =\frac{\lambda^{4} N_{0}}{\pi^{5}|K|^{2}}\left(\frac{a_{0}}{\Lambda^{1+\mu}} \Gamma(1+\mu)+\frac{a_{1}}{\Lambda^{2+\mu}} \Gamma(2+\mu)+\ldots+\frac{a_{n}}{\Lambda^{n+1+\mu}} \Gamma(n+1+\mu)\right)
\end{aligned}
$$

Thus the equation (3) can be rewritten results in equation (11) of $\mathrm{Z}$ factor,

$$
Z_{\text {Mie }}=p_{0} R^{l_{0}}+p_{1} R^{l_{1}}+\ldots+p_{n} R^{l_{n}}
$$

\section{B. Evaluation of Rainfall Rate Estimation based on Rayleigh and Mie Scattering Assumptions}

F. Yoshino [7], Christian Matzler [6], and the others estimate parameters of droplet size distributions, stratiform (Marshall and Palmer), drizzling (Joss-Drizzle), thunderstorm (Joss-Thunderstorm) and realistic rainfall (Laws-Persons) by

\begin{tabular}{|c|c|c|c|}
\hline $\begin{array}{c}\text { Distribution } \\
\text { Function }\end{array}$ & \multicolumn{2}{|c|}{ NO(R) } & $\wedge(\mathbf{R})$ \\
\hline$\overline{\mathbf{L P}}$ & \multicolumn{2}{|c|}{$198 E-5 R^{\wedge}(-0.384)$} & $5.38 R^{\wedge}(-0.186)$ \\
\hline MP & \multicolumn{2}{|r|}{ 8.0E-06 } & $4.1 R^{\wedge}(-0.21)$ \\
\hline JD & \multicolumn{2}{|r|}{ 3.0E-05 } & $5.7 R^{\wedge}(-0.21)$ \\
\hline JT & \multicolumn{2}{|r|}{$1.4 E-06$} & $3.0 R^{\wedge}(-0.21)$ \\
\hline $\begin{array}{c}\text { Distribution } \\
\text { Function }\end{array}$ & $\boldsymbol{\mu}$ & Z-R & Rain Type \\
\hline$\overline{\mathbf{L P}}$ & 2.93 & $378 R^{\wedge} 1.43$ & realistic DSD \\
\hline MP & $\mathbf{0}$ & $298 R^{\wedge} 1.50$ & stratiform rain \\
\hline JD & $\mathbf{0}$ & $120 R^{\wedge} 1.49$ & Drizale \\
\hline JT & $\mathbf{0}$ & $536 R^{\wedge} 1.48$ & Thunderstorm \\
\hline
\end{tabular}
using Normalized distribution (Marshall-Palmer: MP, JossDrizzle: JD, Joss-Thunderstorm: JT and LP distributions). Typical parameters of these different types of rainfall are shown in Table 1. Droplet size distribution, on the other hand, is shown in Figure 1.

TABLE I. PARAMETERS FOR LP, MP, JD, JT DISTRIBUTIONS

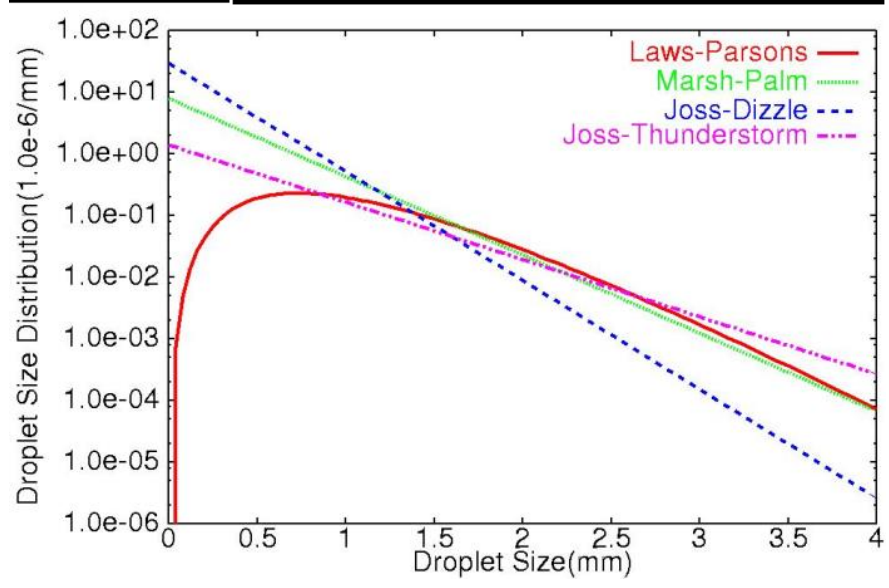

Fig.1. Droplet size distribution of four typical rainfall models

The parameters shown in Table 1 are estimated based on Rayleigh scattering assumption. Thunderstorm is 
characterized as relatively large "a" and comparatively small "b" while stratiform is characterized as relatively small "a" and comparatively large "b". These estimated results are coincident to Z-R Relation which is estimated by RemkoUijlenhoet et al. [14].

Next Mie scattering based Z-R Relation is estimated. In general, the number of droplets is decreasing in accordance with decreasing of droplet size [10]. From Figure 2, it is set that droplet size ranges from 1 to $6.4 \mathrm{~mm}$ while air temperature is assumed to be 20 degree centigrade under the standard atmospheric pressure.

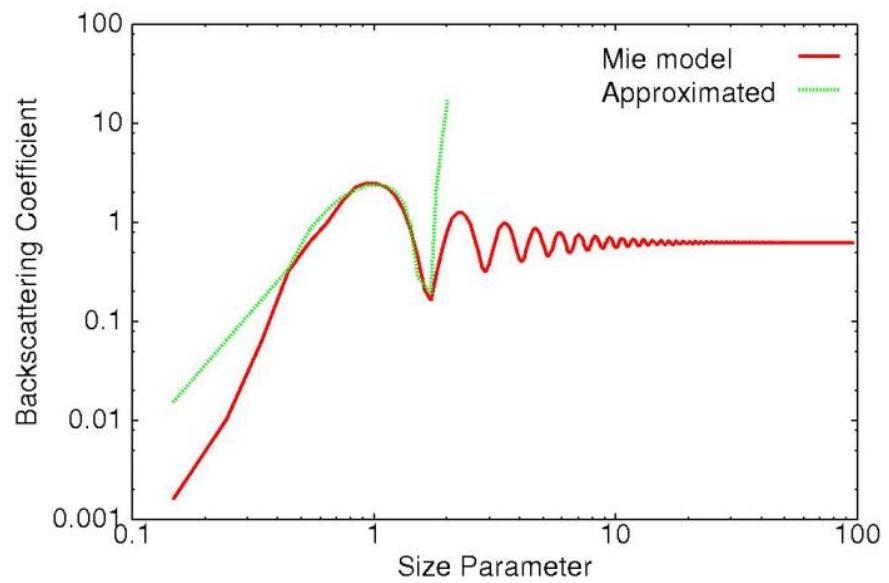

Fig.2. Mie scattering based backscattering coefficient and its approximated coefficient

Wavelength is assumed to be $22 \mathrm{~mm}$ as of TRMM/PR wavelength. According to F. Yoshino, droplet refractive index is assumed to be $8.02-\mathrm{i} 2.00$ through linear interpolation [10]. Backscattering coefficient is calculated with Mie2New which is included in MODTRAN (Radiative transfer software code) [19]. The 6 coefficients in the equation (9) are estimated through least square method by using 5 Legendre functions with Mie scattering code. The estimated coefficients are shown in equation (12).

$\left\{a_{0}, a_{1}, a_{2}, \ldots a_{5}\right\}=\{3.1927,-3.6439,2.0386,3.6681,-3.4678,0.6950\}$

Size parameter which is shown in Figure 2 is expressed as $\pi \mathrm{D}$ in unit of $\mathrm{cm}$. Both Mie scattering based backscattering coefficient and its approximation shows coincidence for the range from 3 to $20 \mathrm{~mm}$ of size parameter. The corresponding droplet size ranges from 1 to $6.4 \mathrm{~mm}$.

Thus Mie scattering based Z-R Relation can be estimated. These are shown in equations (13), (14) and (15)

$$
\begin{aligned}
Z_{\text {strut }}= & \left(1.45 R^{0.2293}+6.34 R^{0.4393}-9.50 R^{0.6493}\right. \\
& \left.+1.78 R^{0.8593}-1.07 R^{1.0693}+5.64 R^{1.2793}\right) * 100 \\
Z_{d r \dot{z}}= & \left(4.86 R^{0.2293}+15.28 R^{0.4393}-16.47 R^{0.6493}\right. \\
& \left.+2.22 R^{0.8593}-0.96 R^{1.0693}+3.64 R^{1.2793}\right) * 100 \\
Z_{\text {Thund }} & =\left(0.46 R^{0.2293}+2.75 R^{0.4393}-5.64 R^{0.6493}\right. \\
& \left.+1.44 R^{0.8593}-1.19 R^{1.0693}+8.54 R^{1.2793}\right)^{*} 100
\end{aligned}
$$

Figure 3 shows $\mathrm{Z}$ factors for three different rainfall types, drizzling, stratiform and thunderstorm under the assumptions of Rayleigh and Mie scatterings.
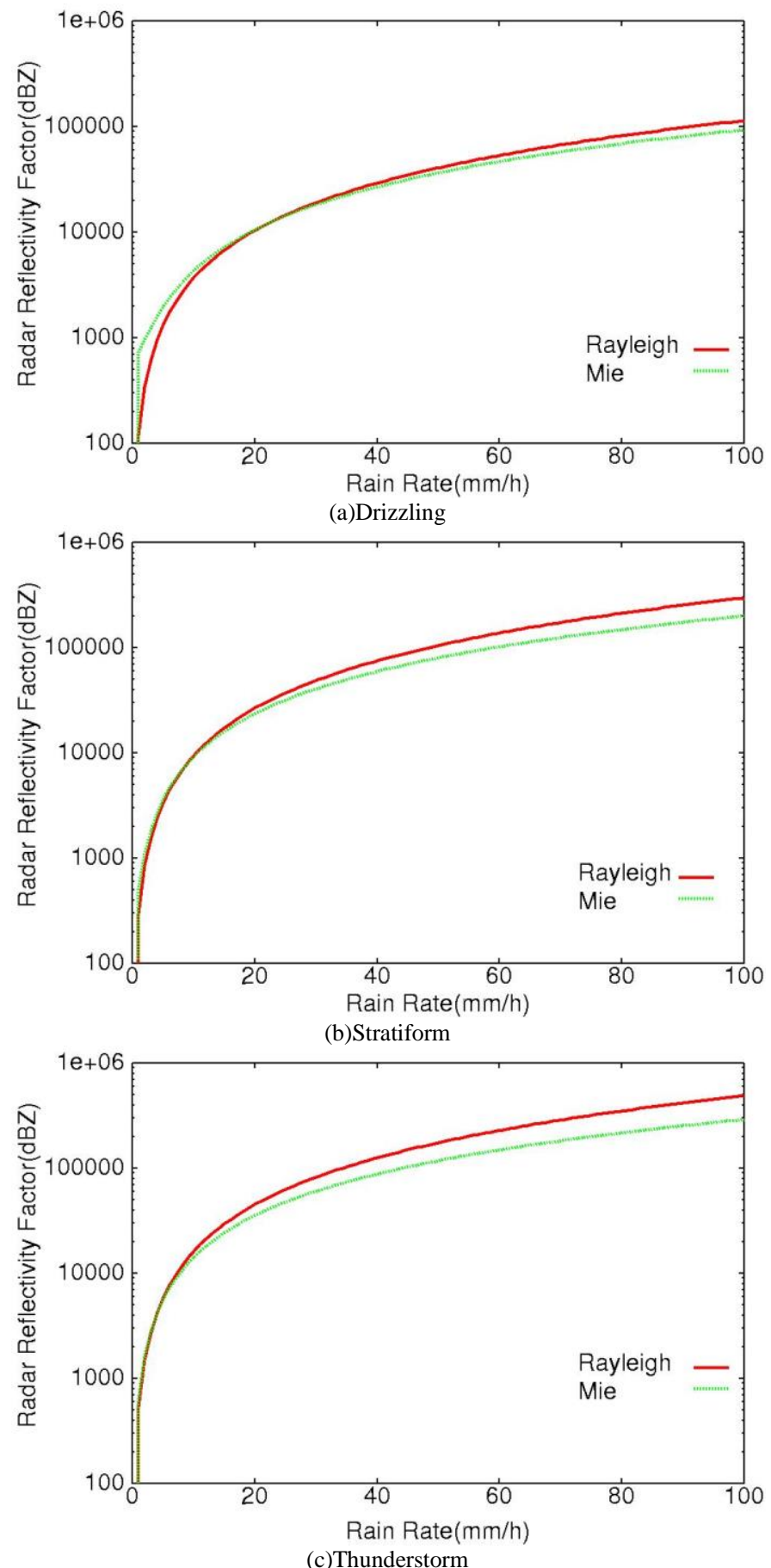

Fig.3. Rayleigh and Mie scattering based Z-R Relations

For relatively small rainfall rate, both Rayleigh and Mie scattering based Z-R Relations are coincident. Meanwhile, the difference between both is getting large in accordance with rainfall rate is increased. Also it is found that the difference between both is getting large in accordance with increasing of droplet size. 


\section{EXPERIEMNTS}

\section{A. Method for Experiment}

TRMM/PR data of $2 \mathrm{~A} 25$ product $(\mathrm{Z}$ value at ground surface after the rainfall attenuation correction) is used. Also ground based rain radar data $(2.8 \mathrm{GHz}$ of radar frequency) is used for validation. The radar site is situated at Houston, Texas and Kwajalein Atoll.TRMM/PR data of Houston is acquired on October 242005 while that of Kwajalein Atoll is acquired on September 15 and 20 2008. These acquisition location and dates are selected from the TRMM/PR GV data for validation of TRMM/PR show heavy rainfall with much greater than $40 \mathrm{~mm} / \mathrm{hr}$ in the year of 2008 .

The radar data is a portion of $\mathrm{GV}$ data for validation of TRMM/PR. Rainfall rate obtained from the GV data are mapped onto longitude / latitude coordinate mesh. Therefore, it is easy to find the location through pattern matching between rainfall rate pattern derived from TRMM/PR and the GV data. Rainfall pattern of Houston derived from TRMM/PR data is compared to ground based radar data of Houston.

Meanwhile, the GV data of Kwajalein Atoll is used for comparison of Rayleigh and Mie scattering based rainfall rate. Rainfall rate of Kwajalein Atoll acquired on September 15 is heavier than September 20. TRMM/PR data at range bin number of 60 for the TRMM/PR data acquired on September 15 shows rainfall while that for September 20 does not show such rainfall. Equation (15) of Z-R Relation which is represented as Mie scattering based rainfall rate estimation is used.

\section{B. Experimental Results}

Figure 4 (a) shows TRMM/PR derived rainfall rate for hurricane Wilma while (b) shows ground based radar data derived rainfall rate acquired at around same time on 24 October 2005. Figure 4 (a) shows narrow swath of TRMM/PR data derived rainfall rate on the imagery data which is derived from VIRS (Visible to Infrared Radiometer which is onboard the same satellite of TRMM). Both rainfall rates show a good coincidence.

Figure 5 (a) and (b) shows vertical profiles of the estimated rainfall rate derived from TRMM/PR data of Kwajalein Atoll acquired on 15 September (a) and on 20 September (b), respectively. Figure 5 also shows comparison of the estimated rainfall rate between Rayleigh and Mie scattering assumption for relatively heavy rainfall (September 15) and comparatively light rainfall (September 20), respectively. Rrayleigh and Rmie denote the estimated rainfall rate under the Rayleigh scattering assumption and that under the Mie scattering assumption. On the other hand, Delta R denotes the difference between both estimated rainfall rates. Delta $\mathrm{R}$ near the surface is greater than that in the high altitude. Also Delta $\mathrm{R}$ for heavy rain is greater than that for light rain.

Figure 6 (a) shows the relation between Rrayligh, Rmie as well as Delta $\mathrm{R}$ and true rainfall rate derived from ground based radar data as GV data for relatively heavy rainfall while those for comparatively light rainfall is shown in Figure 6 (b). Figure 6 also shows linear approximation of relation between both.

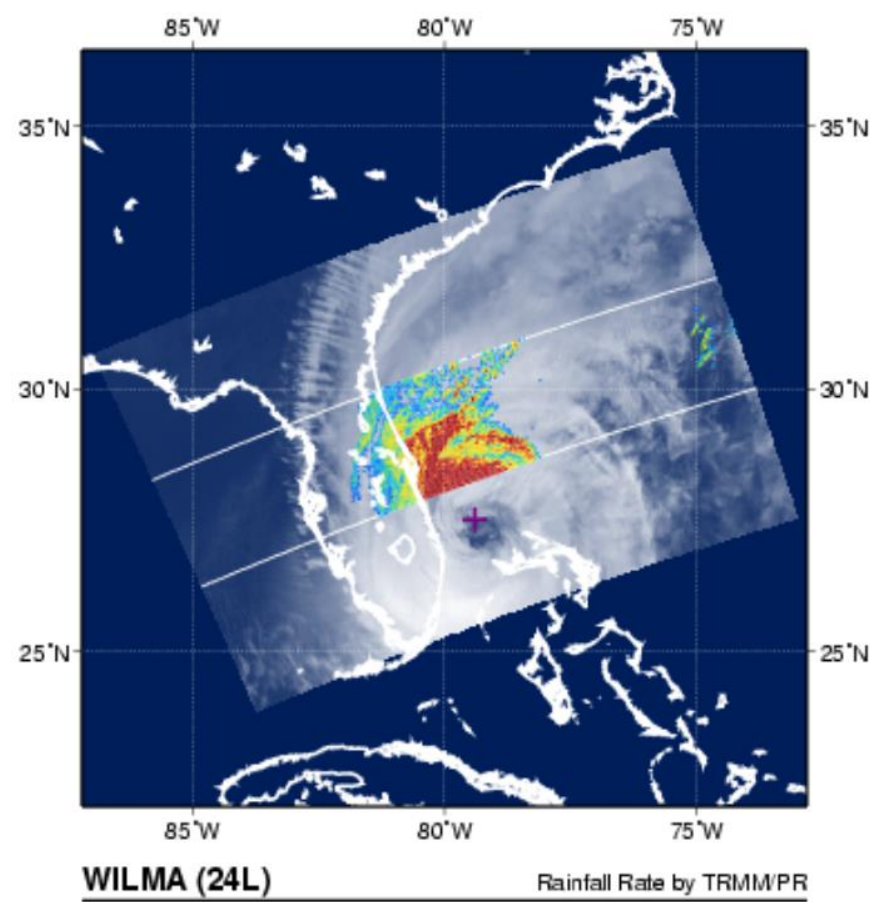

2005-10-24 16:19 (UTC) Orbit Number 45258

2A25.05 1024.45258.6.24L.WILIMA.HDF (Ver.6)

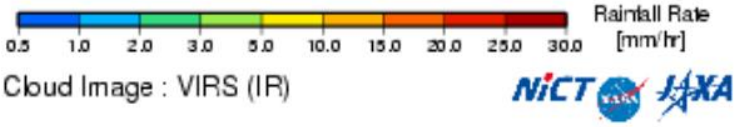

(a)TRMM/PR

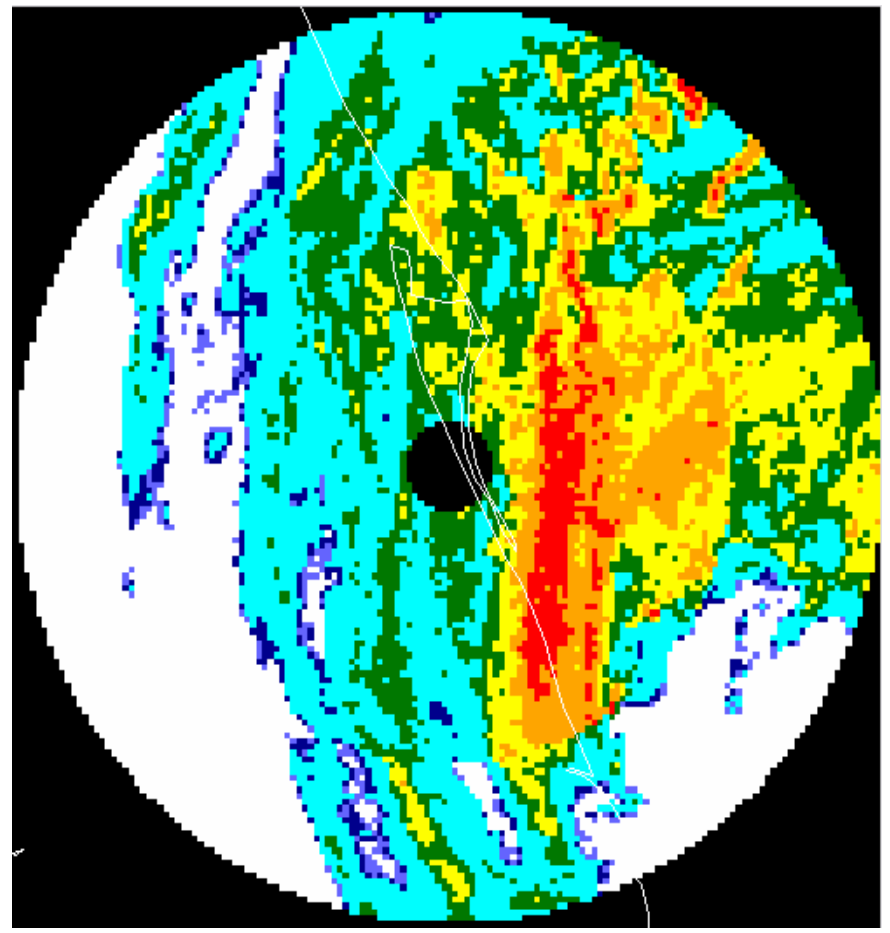

(b)Ground based radar

Fig.4. Comparison of estimated rainfall rate between TRMM/PR and ground based radar 


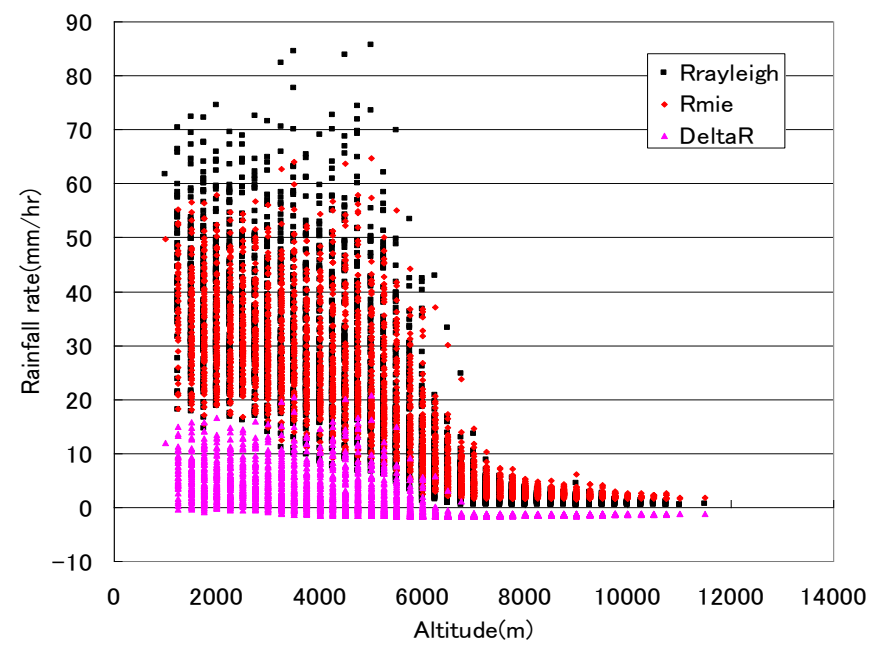

(a) 15 September

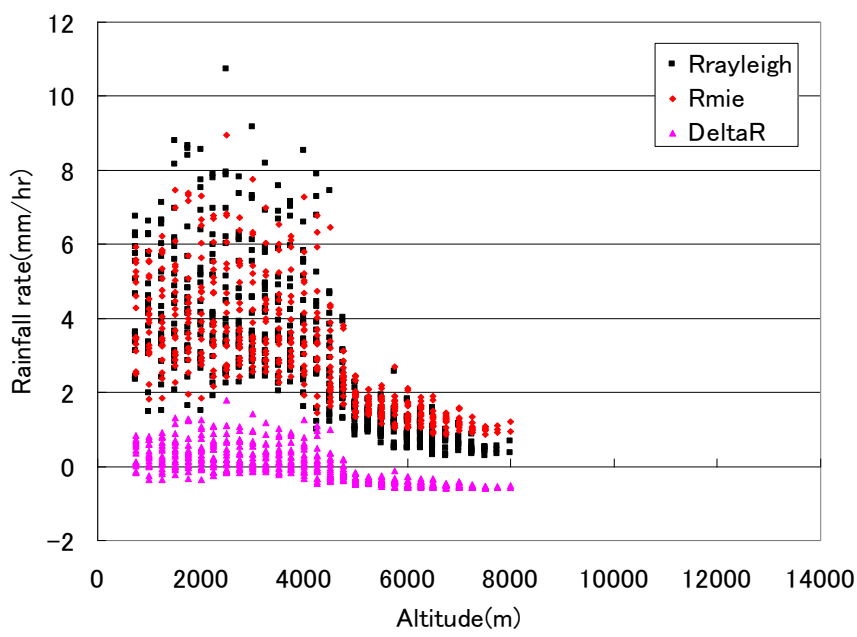

(b) 20 September

Fig.5. Estimated rainfall rate derived from TRMM/PR of Kwajalein Atoll acquired on 15 and 20 September 2008. Comparison of the estimated rainfall rate based on Rayleigh and Mie scattering assumptions.

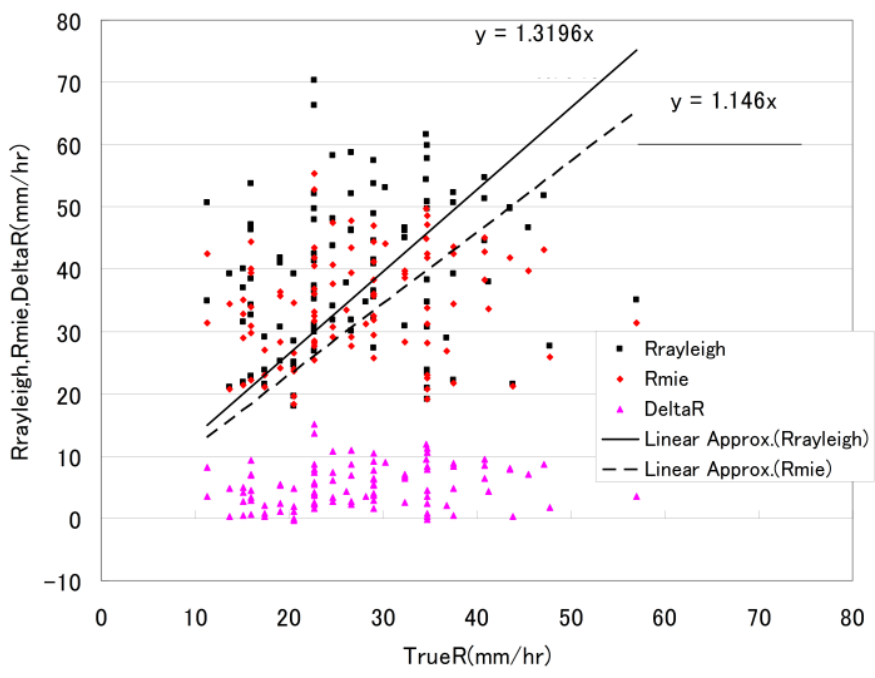

(a)15 September

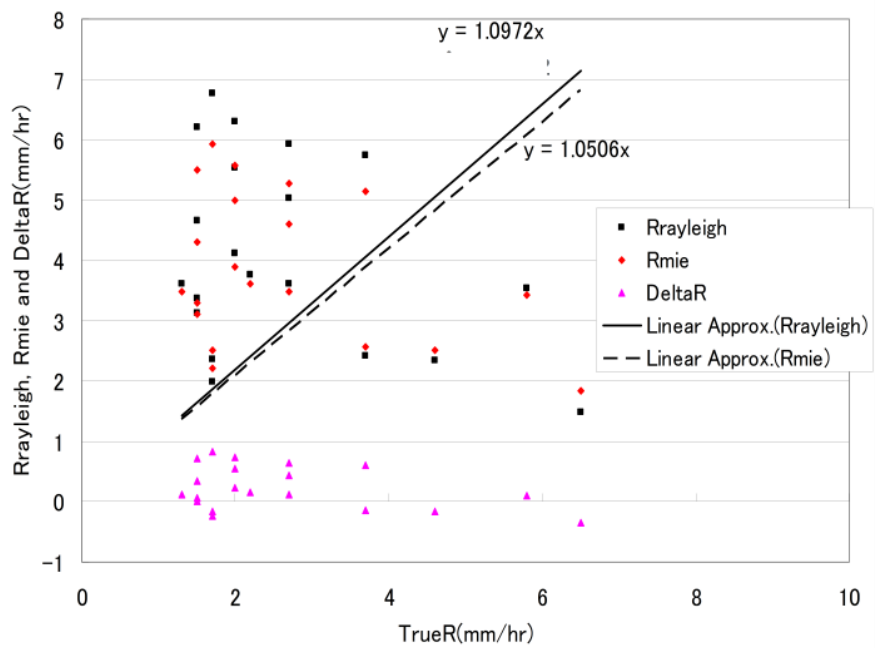

(b)20 September

Fig.6. Relation between Rrayligh, Rmie as well as Delta $\mathrm{R}$ and true rainfall rate derived from ground based radar data as GV data for relatively heavy rainfall while those for comparatively light rainfall

\section{CONCLUSION}

Comparison of the rain rate estimated with the assumptions of Rayleighand Mie scattering is made. We analyzed the different relationships between the radar reflective factor and rain rate (so-called Z-R relationship) with both scattering models for different DSD (droplet size distribution) and rainfall types as the wavelength is $2.2 \mathrm{~cm}$ which is in accord with the band of TRMM/PR. Meanwhile we introduced a discrete ordinates method to retrieve the Z-R relationship for Mie scattering assumption. It is found that the retrieval result can be represented as the sum of some simple $\mathrm{Z}-\mathrm{R}$ relationships. By the analysis of the Z-R relationships estimated from Rayleigh and Mie scattering assumptions in the rain types, we found that the difference of Z-R relationships between Rayleigh and Mie scattering in the thunderstorm that represents the larger raindrop size is larger than that in the drizzle that represent the smaller raindrop size. The followings are concluded,

1) Estimation of Z-R Relation based on Mie scattering theory by using Legendre function of approximation has been conducted.

2) Z-R Relation based on Rayleigh scattering theory can be represented with exponential function while Z-R Relation based on Mie scattering theory can be represented with summation of exponential functions.

3) Z-R Relations based on both Rayleigh and Mie scattering theories are coincident when raindrop size is relatively large while these are not coincident when raindrop size is small through analysis with four types of size distributions of stratiform rain, drizzling and thunder storm as well as actual rain.

4) In particular, the difference of Z-R Relation between thunder storm and stratiform is greatest followed by between drizzling. 
5) Rainfall rate estimation based on Mie scattering theory is much closer to ground based rain radar derived rainfall rate rather than that based on Rayleigh scattering theory for the hurricane "Wilmer" which hit Florida peninsula on 24 October 2005 observed with TRMM/PR of which raindrop size is relatively large at the boundary layer.The reason for this would be the fact that backward scattering is relatively small and forward scattering is comparatively large for Mie scattering while backward and forward scattering are almost same for Rayleigh scattering.

\section{ACKNOWLEDGMENT}

The author would like to thank Dr. Xing MingLiang of NOAA/NESDIS for his effort to conduct the experiments.

\section{REFERENCES}

[1] K.Okamoto, edit. Earth Environment Observations, Ohm Publishing Co. Ltd., 1999.

[2] R. Meneghini, et. al., Use of the surface reference techniques for path attenuation estimates from the TRMM precipitation radar, Journal of Applied Meteorology, 39, pp.2053-2070, 2000.

[3] Meneghini, R., S. W. Bidwell, R. Rincon, and G. M. Heymsfield, Differential-frequency Doppler weather radar: Theory and experiment, RADIO SCIENCE, 38(3), 2003.

[4] M. Šálek, J.L. Cheze, J. Handwerker, L. Delobbe and R. Uijlenhoet, Radar techniques for identifying precipitation type and estimating quantity of precipitation, Document of COST Action 717, WG 1, 2004.

[5] K.K. Comstock, R. Wood, S.E. Yuter, C.S. Bretherton, Reflectivity and rain rate in and below drizzling stratocumulus, Quarterly Journal of the Royal Meteorological Society, 130:603603, pp.2891-2918, 2004.

[6] C. Mätzler, Drop-Size Distributions and Mie Computations for Rain,InstitutfürAngewandtePhysik, Research Report No. 2002-16, 2002

[7] L.J. Battan, Radar Observation of the Atmosphere, Univ. of Chicago Press, Chicago, Illinois, 324p., 1973.

[8] TRMM Precipitation Radar Team,Tropical Rainfall Measuring Mission ( TRMM ) Precipitation Radar Algorithm, Instruction Manual for Version 6, JAXA and NASA, 2005.

[9] M. Marzoug, and P.Amayenc, A class of single frequency algorithms for rain rate profiling from a spaceborne radar, 1. Principle and tests from numerical simulations, Journal of Atmospheric and Oceanic Technology, 11, pp.1480-1506, 1994.

[10] F.Yoshino, Radar Hydrology, MorikitaShuppan Publishing Co. Ltd, 2002.
[11] D. Atlas, C.W. Ulbrich, Path- and Area-Integrated Rainfall Measurement by Microwave Attenuation in the $1-3 \mathrm{~cm}$ Band, Journal of Applied Metrology, 16(12), pp.1322-1331, 1977

[12] R. Gunn, G.D. Kinzer, THE TERMINAL VELOCITY OF FALL FOR WATER DROPLETS IN STAGNANT AIR, Journal of the Atmospheric Sciences, 6(4), pp.243-248, 1949.

[13] C.W. Ulbrich, Natural Variations in the Analytical Form of the Raindrop Size Distribution, Journal of Applied Meteorology, 22(10), pp.17641775, 1983.

[14] U. Remko, Raindrop size distributions and radar reflectivity-rain rate relationships for radar hydrology, Hydrology and Earth System Sciences, 5(4), pp.615-627, 2001

[15] T. Iguchi, and R. Meneghini, Intercomparison of single frequency methods for receiving a vertical rain profile from airborne and spaceborne radar data, Journal of Atmospheric and Oceanic Technology, 11, 1507-1516, 1994.

[16] Iguchi, T., T.Kozu, R.Meneghini, J.Awaka and K.Okamoto, Rainprofiling algorithm for the TRMM precipitation radar, Journal of Applied Meteorology, 39, 2038-2052, 2000.

[17] Murray R. Spiegel, McGraw-Hill Mathematical Formulas - Numerical Tables Handbook, Ohm Publishing Co. Ltd., 1998.

[18] A.R. Jameson, and A. B. Kostinski, Spurious power-law relations among rainfall and radar parameters, Q. J. R. Meteorol. Society, 128, pp.2045-2058, 2002.

[19] A. Berk, L.S. Bernstein, and D.C. Robertson, MODTRAN: A Moderate Resolution Model for LOWTRAN 7, Air Force Geophysics Laboratory Technical Report GL-TR-89-0122, Hanscom AFB, MA

[20] K.Okamoto, S. Kasane, Observed Results and Research and Development of TRMM/PR, Invited Paper of Journal of the Japanese Institute of Electronics, Information Communications, J91-B, 7,723733,2008 .

\section{AUTHORS PROFILE}

Kohei Aarai He received BS, MS and PhD degrees in 1972, 1974 and 1982, respectively. He was with The Institute for Industrial Science and Technology of the University of Tokyo from April 1974 to December 1978 and also was with National Space Development Agency of Japan from January, 1979 to March, 1990. During from 1985 to 1987, he was with Canada Centre for Remote Sensing as a Post Doctoral Fellow of National Science and Engineering Research Council of Canada. He moved to Saga University as a Professor in Department of Information Science on April 1990. He was a councilor for the Aeronautics and Space related to the Technology Committee of the Ministry of Science and Technology during from 1998 to 2000. He was a councilor of Saga University for 2002 and 2003. $\mathrm{He}$ also was an executive councilor for the Remote Sensing Society of Japan for 2003 to 2005. He is an Adjunct Professor of University of Arizona, USA since 1998. He also is Vice Chairman of the Commission-A of ICSU/COSPAR since 2008. He wrote 30 books and published 332 journal papers. 